Supplementary Material to Climate of the Past publication:

\title{
Antarctic ice sheet and oceanographic response to eccentricity forcing during the early Miocene
}

\author{
D. Liebrand ${ }^{1,2}$, L. J. Lourens ${ }^{1}$, D. A. Hodell ${ }^{3}$, B. de Boer ${ }^{4}$, R. S. W. van de Wal ${ }^{4}$, and H. Pälike ${ }^{2}$ \\ ${ }^{1}$ Department of Earth Sciences, Faculty of Geosciences, Utrecht University. Budapestlaan 4, 3584 CD \\ Utrecht, The Netherlands \\ ${ }^{2}$ School of Ocean and Earth Science, University of Southampton, National Oceanography Centre, \\ Southampton, European Way, Southampton SO14 3ZH, UK \\ ${ }^{3}$ Department of Earth Sciences, University of Cambridge, Downing Street, Cambridge CB2 3EQ, UK \\ ${ }^{4}$ Institute for Marine and Atmospheric research Utrecht (IMAU), Utrecht University, Princetonplein 5, 3584 \\ CC Utrecht, The Netherlands
}

Correspondence to: D. Liebrand (diederik.liebrand@noc.soton.ac.uk) 
Same sample reproducability:
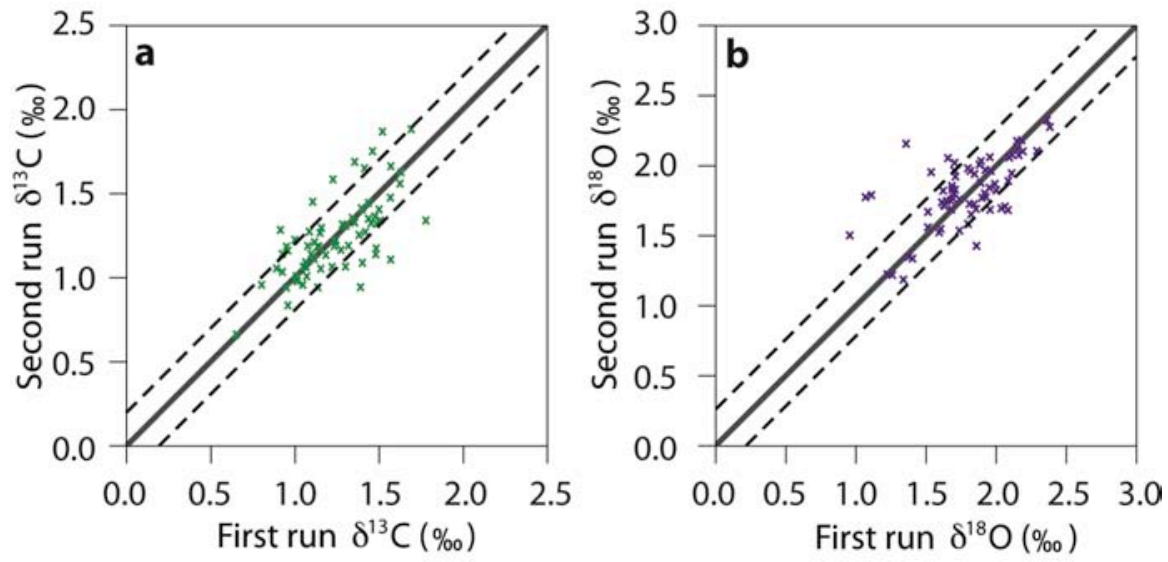

Inter-laboratory comparison:
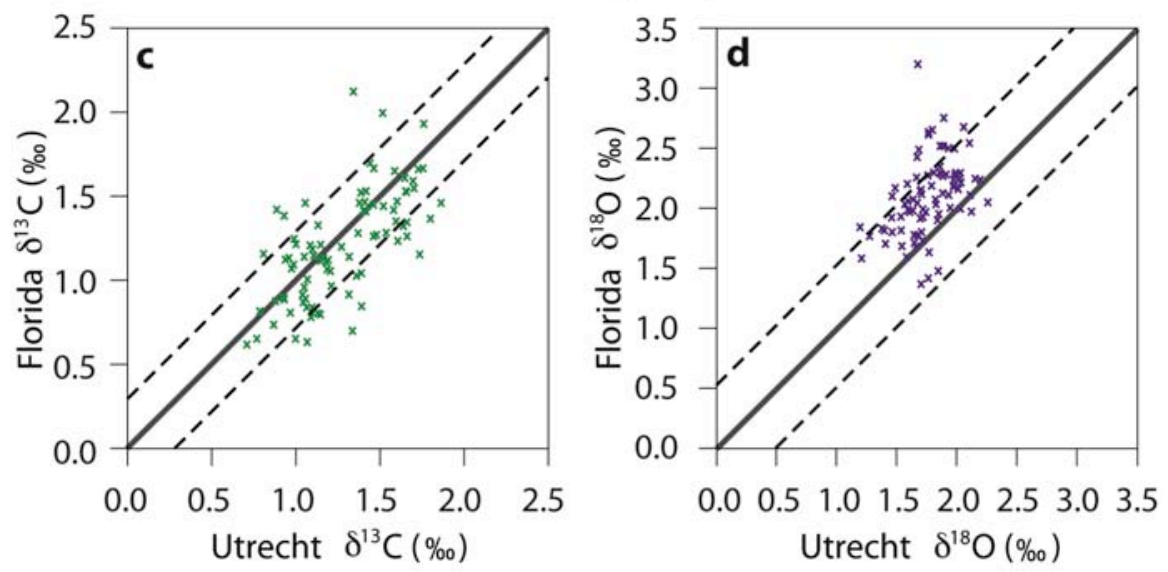

$=$ Ideal

$----=2 \sigma$ upper and lower boundaries

Supp. Fig. 1. Data reproducibility. (a) Reproducibility between the first and second run $\delta^{13} \mathrm{C}$ of the same samples (not necessarily the same foraminifer) on the three inter-calibrated mass spectrometers. (b) As in panel (a), but then for $\delta^{18} \mathrm{O}$. (c) Reproducibility of $\delta^{13} \mathrm{C}$ between measurements done at the University of Florida (UF) and Utrecht University (UU), on specimens from the same sample. (d) As in panel (c), but then for $\delta^{18} \mathrm{O}$. 

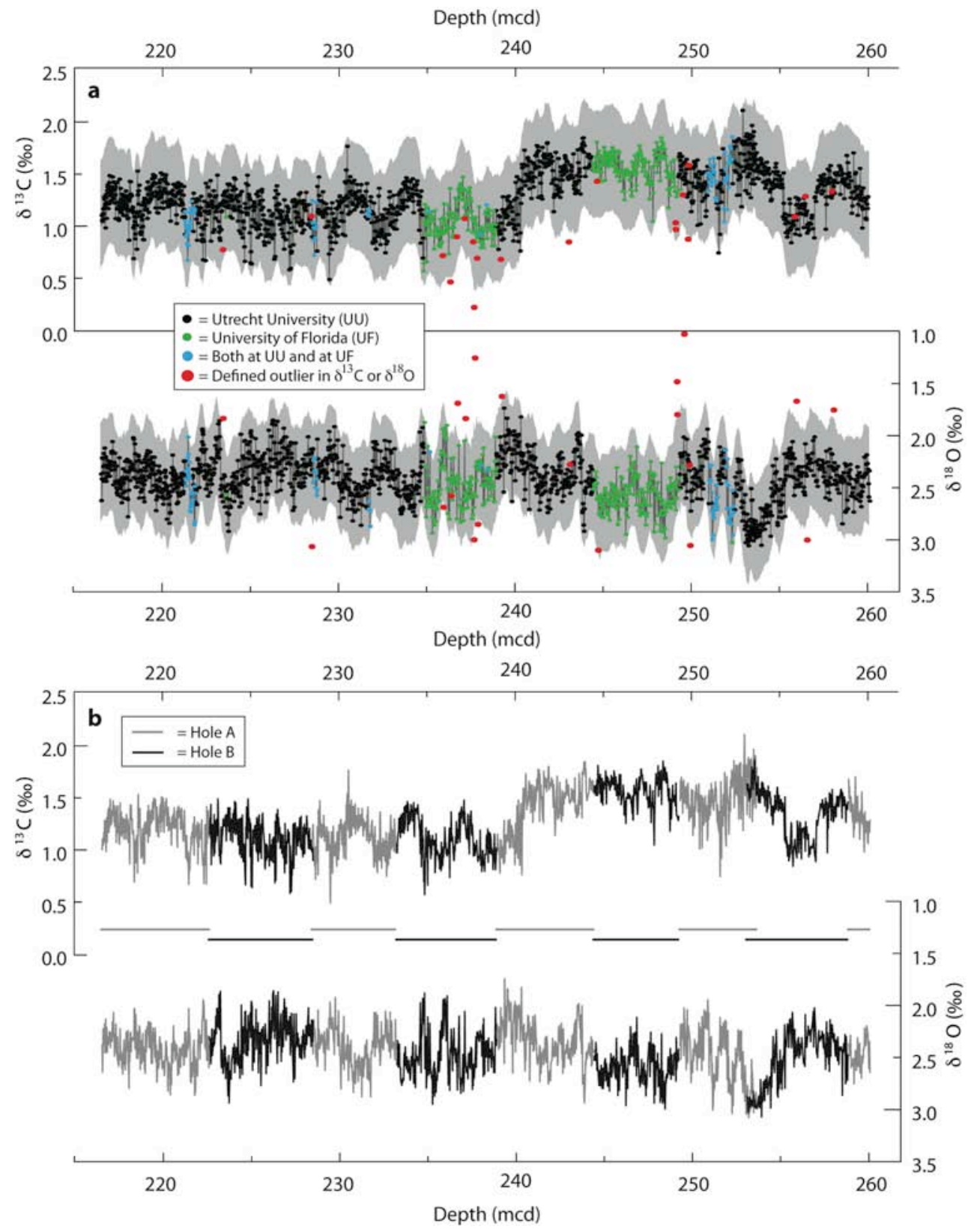

Supp. Fig. 2. Outlier removal and the splice. (a) Specification in which lab each stable isotope measurement has been done. Outliers were defined by an upper and lower boundary of 2 standard deviations (of the entire series) added or subtracted from a 13-point moving average (gray areas). Outliers defined in $\delta^{13} \mathrm{C}$ or in $\delta^{18} \mathrm{O}$ were removed from both records because of the paired analysis. Depth scale is in meters composite depth (mcd). (b) Splice of Site 1264, showing from which hole the samples were taken. 

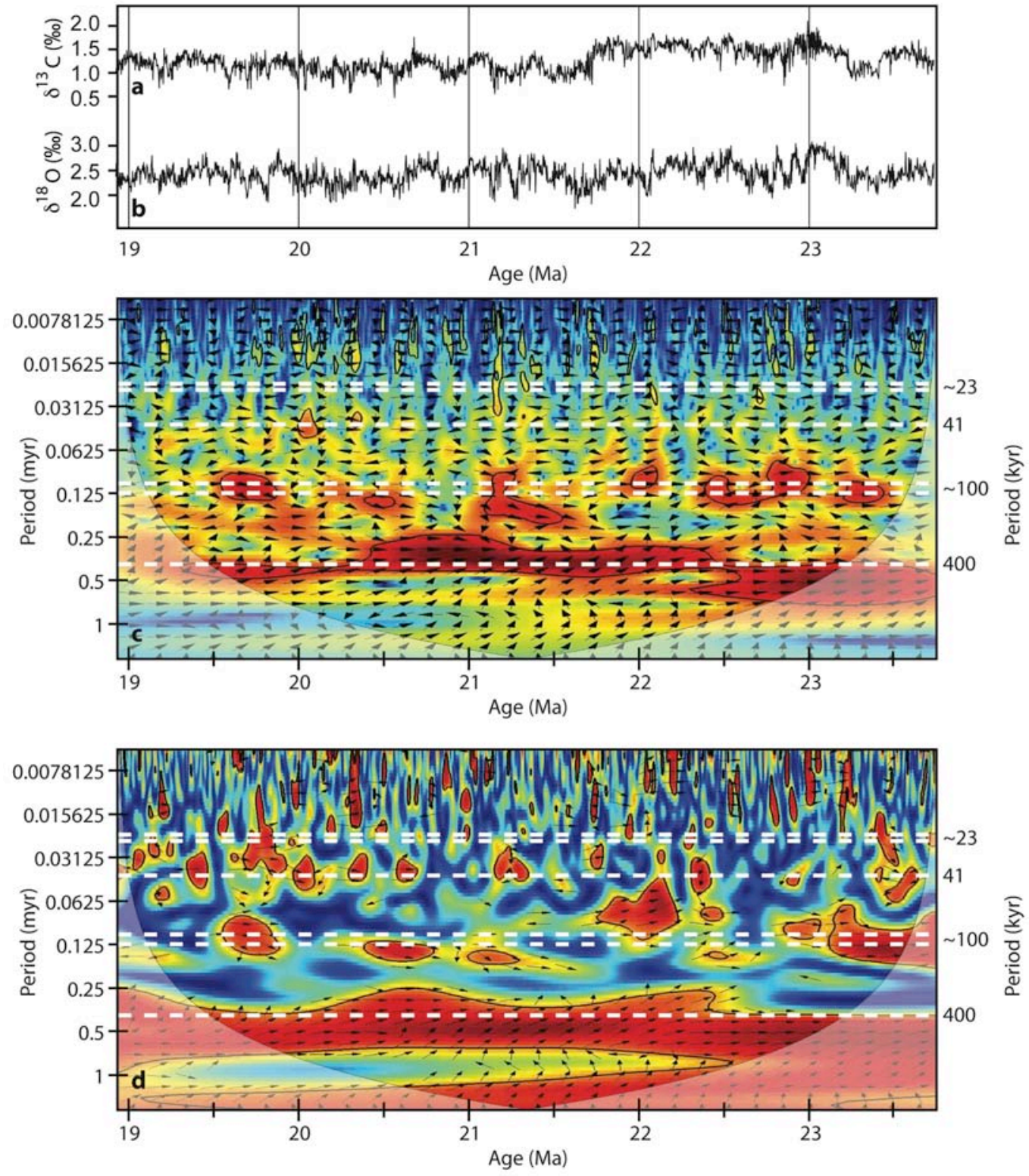

Supp. Fig. 3. Cross wavelet transform and wavelet coherence. (a) $\delta^{13} \mathrm{C}$ record from Site 1264 of the Walvis Ridge. (b) $\delta^{18} \mathrm{O}$ record from Site 1264 of the Walvis Ridge. (c) Cross wavelet transform analysis between the $\delta^{18} \mathrm{O}$ and $\delta^{13} \mathrm{C}$ records indicating regions in time frequency space where the time series show high common power (Grinsted et al., 2004). Phase arrows pointing right means $\delta^{18} \mathrm{O}$ and $\delta^{13} \mathrm{C}$ are in-phase. Phase arrows pointing left means $\delta^{18} \mathrm{O}$ and $\delta^{13} \mathrm{C}$ are in anti-phase. Phase arrows pointing up means that $\delta^{18} \mathrm{O}$ is leading $\delta^{13} \mathrm{C}$ by $90^{\circ}$. Phase arrows pointing down means that $\delta^{13} \mathrm{C}$ is leading $\delta^{18} \mathrm{O}$ by $90^{\circ}$. Black lines represent $>95 \%$ significance levels. (d) Wavelet coherence analysis (Grinsted et al., 2004) between the $\delta^{18} \mathrm{O}$ and $\delta^{13} \mathrm{C}$ records indicating regions in time frequency space where the two time series co-vary. However, they do not necessarily have high power on these frequencies (Grinsted et al., 2004). Phase arrows representation as in panel (a). Black lines represent $>95 \%$ Monte Carlo significance levels. Regions in the time frequency space where both records show much power (panel (c)) and where both records are coherent (panel (d)) represent the coupling between climate states and the changes in the oceanic carbon reservoir which has also been described at other Sites (e.g. Zachos et al., 1997, 2001;Paul et al., 2000). 


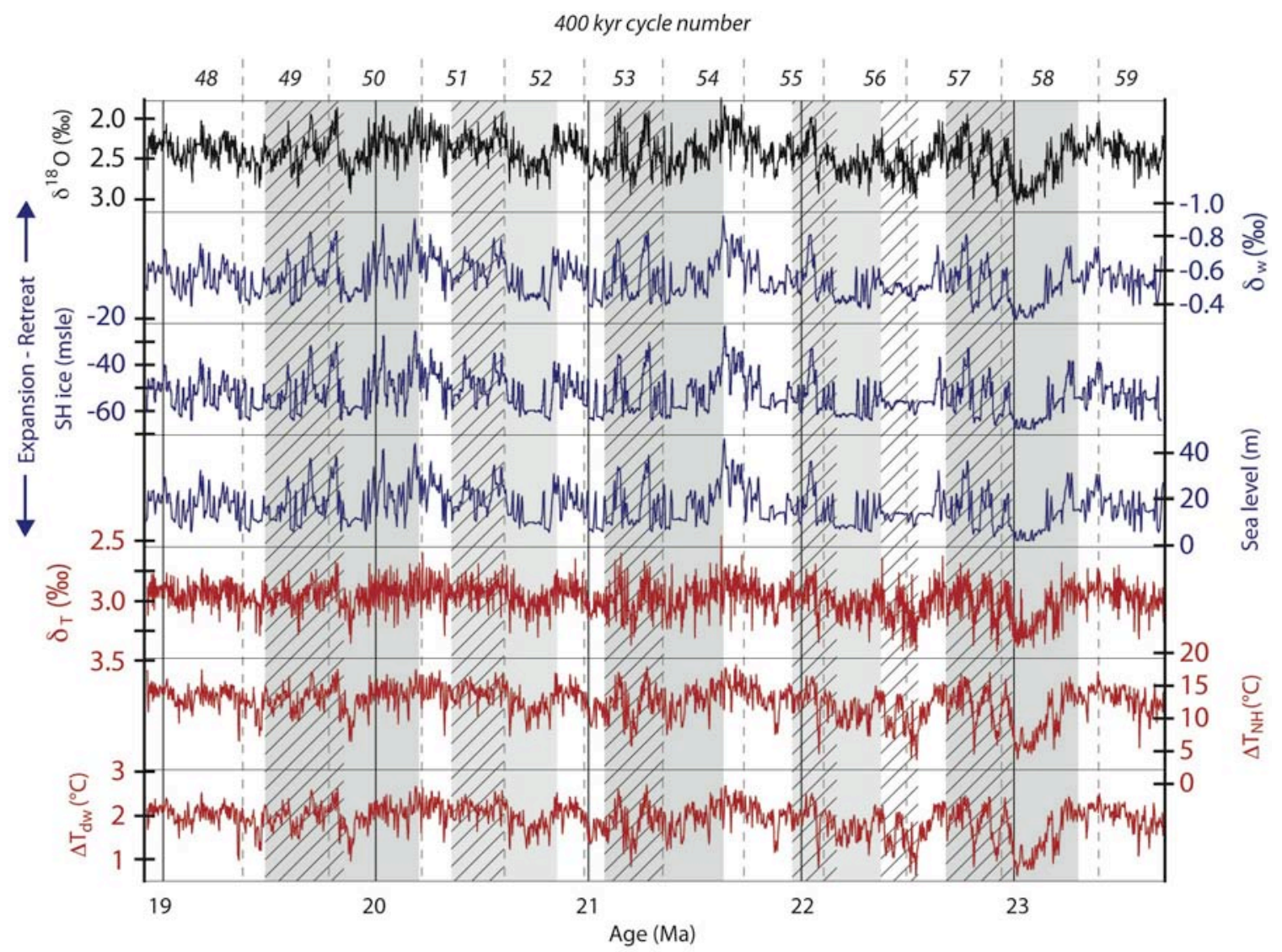

Supp. Fig. 4. 1-D inverse modelling output. The $\delta^{18} \mathrm{O}$ record (as measured), $\delta_{\mathrm{w}}$ (seawater contribution, from ice volume, to $\delta^{18} \mathrm{O}$ ), ice on Antarctica, eustatic sea level, $\delta_{\mathrm{T}}$ (temperature contribution to $\delta^{18} \mathrm{O}$ ), Northern Hemisphere (40-80 Latitude) annual average temperature (relative to present day) and deepwater temperature (relative to present day) calculated by the 1-D model (De Boer et al., 2010), are depicted. The $\delta_{\mathrm{w}}, \delta_{\mathrm{T}}$, and $\Delta \mathrm{T}_{\mathrm{dw}}$ values all represent oceans average values, because the model cannot resolve single water masses and/or oceans. Gray areas indicate cooling periods with reduced $\sim 100 \mathrm{kyr}$ power, gray and striped areas indicate $\sim 100 \mathrm{kyr}$ worlds, white areas are intermediate phases characterized by greater non-linear response to eccentricity modulated precession.

\section{References}

De Boer, B., Van de Wal, R. S. W., Bintanja, R., Lourens, L. J., and Tuenter, E.: Cenozoic global icevolume and temperature simulations with 1-D ice-sheet models forced by benthic $\delta^{18} \mathrm{O}$ records, Ann. Glaciol., 51, 23-33, 2010.

Grinsted, A., Moore, J. C., and Jevrejeva, S.: Application of the cross wavelet transform and wavelet coherence to geophysical time series, Nonlinear Proc. Geoph., 11, 561-566, 2004.

Paul, H. A., Zachos, J. C., Flower, B. P., and Tripati, A.: Orbitally induced climate and geochemical variability across the Oligocene/Miocene boundary, Paleoceanography, 15, 471-485, 2000.

Zachos, J. C., Flower, B. P., and Paul, H. A.: Orbitally paced climate oscillations across the Oligocene/Miocene boundary, Nature, 388, 567-570, 1997.

Zachos, J. C., Shackleton, N. J., Revenaugh, J. S., Pälike, H., and Flower, B. P.: Climate response to orbital forcing across the Oligocene-Miocene boundary, Science, 292, 274-278, 2001. 